Peer-Reviewed Article

ISSN: 2162-3104 Print/ ISSN: 2166-3750 Online

Volume 6, Issue 4 (2016), pp. 829-842

(C) Journal of International Students

http://jistudents.org/

\title{
Student Success Through \\ Leadership Self-efficacy: A Comparison of International and Domestic Students
}

\author{
David H. K. Nguyen \\ University of North Dakota, USA
}

\begin{abstract}
There is scarce research that examines the leadership experiences of international students on campus. Leadership capacity and efficacy are important indicators of success in higher education and are linked to important academic, career, and life benefits, such as career and leadership aspirations, work performance, the ability to cope and overcome stereotypes, and the adaptation to and persistence in the face of challenging situations. This quantitative study focuses on international students' confidence in their leadership abilities while studying in a foreign country and system in comparison with their domestic student peers. Findings suggest that college campuses and higher education professionals need to do a better job at engaging their international students in leadership opportunities while being culturally relevant.
\end{abstract}

Keywords: International student, leadership self-efficacy, student involvement

Research has exposed multiple challenges of international students while studying on their American campuses, but surprisingly there is scarce research examining approaches to involve international students in activities or examines their perspectives on student involvement to overcome these barriers. Integrating international students into the existing campus culture can be challenging (Andrade, 2006). Student involvement and participation in co-curricular activities can have a positive effect on students' academic and social outcomes on campus. Along with involvement and participation, leadership is also an important indicator of success in higher education 
(Astin \& Astin, 2000; Roberts, 2003). Leadership capacity and efficacy are linked to important academic, career, and life benefits, such as career and leadership aspirations, work performance, the ability to cope and overcome stereotypes, and the adaptation to and persistence in the face of challenging situations (Day, Harrison, \& Halpin, 2009; Hannah, Avolio, Luthans, \& Harms, 2008; Machida \& Schaubroeck, 2011). As a result, increasing leadership opportunities for international students will not only increase their educational success and career aspirations, but it will also be critical to integrating them on campus and developing their own diverse perspectives.

Since research on the development of leadership capacity in international students is absent from the national discourse in higher education, the purpose of this study was to examine whether students' leadership self-efficacy was impacted by their college environments (LSE $\mathrm{Lost}$. More particularly, the study compared international students with their domestic student peers. Through quantitative analyses, this study utilized national data to make this comparison with the influence of their campus environments.

\section{LEADERSHIP SELF-EFFICACY \& STUDENT SUCCESS}

This social construction of leadership has resulted in over 200 definitions and understandings of leadership behavior and leadership development (Rost, 1991). It is not surprising that most people do not understand what the concept of leadership really means (Burns, 1978). For the purposes of this study, leadership is defined in the post-industrial philosophy based on relational, reciprocal, and value-based models (Rost, 1991), which more closely reflects the social justice missions of higher education institutions. Leadership responds to the modern needs of society as a group through which purposeful and ethical engagement of individual energy and influence create change that benefits oneself and others and is collaborative with an authentic and positive approach (Avolio \& Gardner, 2005; Rost, 1991). Leadership development is the process of expanding one's capacity to be effective in leadership roles (McCauley, Van Veslor, \& Rudeman, 2010). For the purposes of this study, leadership development has focused more on developing human capital by focusing on individual intra-personal abilities instead of social capital and investing in interpersonal development and community relationships compared to the industrial philosophy of leadership and developing individual skills and abilities (Komives, Owen, Longerbeam, Mainella, \& Osteen, 2005).

Given that leadership is an integral purpose of higher education (Dugan \& Komives, 2007), it is important to understand how students fit into this complex concept. Komives, et al. (2005) found that as students 
entered college, their approach to leadership appeared to be consistent to the industrial forms of the leader-centric and personal abilities models. As students developed throughout their years in higher education, their understanding of leadership shifted to become more relational, similar to the post-industrial leadership model (Komives, et al., 2005). This provides an important awareness to the present study that individuals' concept of leaders and leadership can change over time. Students' college experiences can change the way they think about leadership, which can also shift their perceptions of leadership efficacy.

Leadership self-efficacy, grounded in social cognitive theory, is the belief that one has the capabilities and resources to perform a specific task leadership. This personal belief can change based on different factors of function, such as self-esteem, competency, and environment (McCormick, Tanguma, \& Lopez-Forment, 2002). It can also be affected by how a person learns behaviors throughout his or her development, which influences his or her judgment and decision-making (Bandura, 1997).

Chemers (2000) describes leadership self-efficacy as a basis from which to understand one's performance in organizing and leading others and asserts that one's confidence can help develop mastery to become a better leader. In other words, self-efficacy in leadership refers to one's confidence in his or her ability to lead, and this frequently impacts whether or not one decides to lead (Hannah, Avolio, Luthans, \& Harms, 2008; Komives \& Dugan, 2010; Murphy, 2002; Paglis, 2010). It has been found that selfefficacy is highly related to the frequency that a person reported an attempt to lead (McCormick, Tanguma, \& Lopez-Forment, 2002). However, efficacy is fluid and is influenced by environmental factors that may either leverage or constrain an individual's perceptions of his or her capacity for leadership (Bandura, 1997). Due to a myriad of challenges, international students may have different leadership efficacies than their domestic student peers depending on their learning environments. Enhancing international students' efficacy for leadership may create positive environments for positive academic success and career outcomes.

\section{LEADERSHIP SELF-EFFICACY OF INTERNATIONAL STUDENTS}

For the purposes of this study, international students are people from other countries who come to the United States for the primary purpose of obtaining a degree (Anderson, Carmichael, Harper, \& Huang, 2009; Robertson, Line, Jones, \& Thomas, 2000). It is important to note that international students do not include those who are in the United States as asylees, refugees, permanent residents, or any other immigration category that allows long-term legal presence in the United States. Student leadership for international students is an area that has yet to be researched, 
and specifically, the understanding of leadership self-efficacy of international students is poorly developed. Leadership self-efficacy has been studied in a myriad of other student populations from women STEM students (Dugan, Fath, Howes, Lavelle, \& Polanin, 2013), commuter students (Dugan, Garland, Jacoby, \& Gasiorski, 2008), students of different races (Kodama \& Dugan, 2013), to GLBTQ+ students (Martinez, Ostick, Komives, \& Dugan, 2007), among others. Collectively, international students are becoming an increasingly relevant student population on American campuses and a student population that should not be ignored.

Although there is no clear evidence on how college environments impact leadership self-efficacy for international students, understanding the demographic and environmental predictors of leadership self-efficacy will provide an understanding of areas to examine coupled with the current research on international students. Anderson, Carmichael, Harper \& Huang (2009) suggested that institutions should better facilitate international student engagement in campus activities through participation in cocurricular activities allowing international students the opportunity to meet new people and make new friends - which are important to a successful transition - adapt to new social networks and navigate the social skills, values, and customs of their new environment, which in turn increases their self-efficacy and confidence (Tomich, McWhirter, \& Darcy, 2003; Toyokawa \& Toyokawa, 2002). In addition, more involvement in cocurricular activities and leadership opportunities will allow international students to voice their needs and concerns on campus.

\section{CULTURAL DIFFERENCES, ENGLISH PROFICIENCY \& LEADERSHIP}

Leadership can be influenced by culture. The differences in leadership style are rooted within different systems of cultural practices and values, and even within a common continent (Chhokar, Brodbeck, \& House, 2013). Ronen and Shenkar (1985) found that clusters of European countries that share similar cultural values also share similar leadership concepts. Countries that cluster together are based on geographical proximity, common language or language groups, religion, economic, political, educational, social development (Hofstede, 1980; Ronon \& Shenkar, 1985). Some of these determine cultural values, such as individualism, impacting the dimensions of leadership. These cultural dimensions are highly correlated with leadership dimensions (Smith, Dugan, \& Trompenaars, 1996).

Although this study does not examine the differences of leadership self-efficacy based on these cultural clusters because of the limitations of the survey, it is important to note the impact of culture on these differences in leadership capacity and self-efficacy. Under leadership categorization 
theory, the better the match between a perceived individual and the leadership concept held by the perceiver, the more likely it is that the perceiver actually visualizes the individual as a leader (Lord \& Maher, 1991). As a result, if leadership concepts differ because of cultural differences between managers and subordinates or colleagues, this can constrain managers' perception of their subordinates' or colleagues' leadership ability (Brodbeck et al., 2000). This could also impact the subordinate/colleague's leadership self-efficacy. Likewise, if a student, faculty, or staff campus leader perceives an international student's cultural difference as not having leadership capacity, it is unlikely that the student, faculty, or staff campus leader will encourage the international student to engage in campus leadership opportunities. These differences in leadership dimensions may also impact international students' self-efficacy of leadership, particularly on the host campus in their host country and culture.

While English proficiency can also impact international students' lack of confidence (Leong, 2015), the instrument used for the purposes of this study did not ask for language proficiency as a demographic variable. The study was unable to explore whether status as international student could be a proxy for English proficiency. In addition, while international students come to campus from other countries, this does not assume that they are coming from non-English speaking countries. While culture and language proficiency are important aspects to leadership, it is a limitation of this study and of the instrument.

\section{THEORETICAL AND CONCEPTUAL FRAMEWORKS}

Bandura's (1977) Social Cognitive Theory provides a model for understanding human behavior as the exercise of control in given situations, which is influenced by individual appraisals of their ability to perform. Social Cognitive Theory serves as the theoretical framework for this study because it is the theoretical foundation for leadership self-efficacy. An individual's self-efficacy, or appraisal of ability, would influence an individual's behavior to participate in leadership. From the theory of selfefficacy, a student is concerned with their environment, their actions, and how they perceive their actions in a particular environment. Connecting this to leadership theory is how leadership self-efficacy evolves through a related theory of Leadership Identity Development, which provides understanding how individuals come to think of themselves in terms of the leadership process (Komives, Owen, Longerbeam, Mainella, \& Osteen, 2005). The relationship between one's understanding of their ability and their appraisal to perform as leaders are connected to his or her involvement experiences, which would influence his or her's leadership self-efficacy. 
Astin's (1993) Inputs-Environment-Outcome (IEO) College Impact Model, which allows the researcher to "assess the impact of various environmental experiences by determining whether students grow or change differently under varying environmental conditions" (p. 7), is the conceptual framework that influenced the Multi-Institutional Study of Leadership (MSL) instrument and is chosen for its cross-sectional design rather than the traditional longitudinal format. While Astin's (1991) traditional IEO model assumes that data collection happens at a minimum of two different points to capture change, the model was adapted for the MSL from the pre-/postassessment to a design that collected retrospective data at a single point. As a result, the MSL instrument asks students to retroactively reflect upon their prior knowledge and experiences. This then/now approach provides a more accurate measure of self-reported leadership development by reducing the amount of response shift bias (Howard, 1980; Howard \& Dailey, 1979; Rohs, 1999, 2002; Rohs \& Langone, 1997). Therefore, while the participants were in college, they answered questions that asked about their pre-collegiate activities and characteristics while also capturing environmental data, such as their current college leadership, institutional type, student status, racial group, perceptions of campus climate, and class standing (Astin, 1993; Dugan, 2011; Pascarella \& Terenzini, 2005). The purpose of this model is to allow researchers to modify the inputs or students' background characteristics so that a more representative estimate of the influences of different college environments have on student outcomes (Astin, 1991). The independent variables in this study are the inputs and environments, while the outcomes are the dependent variables.

\section{RESEARCH METHODS}

\section{Multi-Institutional Study of Leadership (MSL)}

This study employed data from the 2012 Multi-Institutional Study of Leadership (MSL). The MSL was designed to examine and understand college student leadership development and the impact of college environments on leadership outcomes (Dugan \& Komives, 2007). The instrument is based on Astin's (1991) College Impact Model that controls for pre-collegiate characteristics, inputs (I), while assessing the impact of college environments (E) on student outcomes (O). The IEO model uses a longitudinal design with pre- and post-tests. The purpose of the MSL is to enrich already existing knowledge on college student leadership development and the ways in which higher education as a context can influence how the development of leadership capacity takes place (Dugan, Komives, \& Associates, 2006). It is a national study of college student development leadership that explores a variety of factors on leadership and employs a quantitative, comparative, cross-sectional design through survey 
methodology (Groves, Fowler, Couper, Lepkowski, Singer, \& Tourangeau, 2004).

Figure 1: Multi-Institutional Study of Leadership Conceptual Model (2012

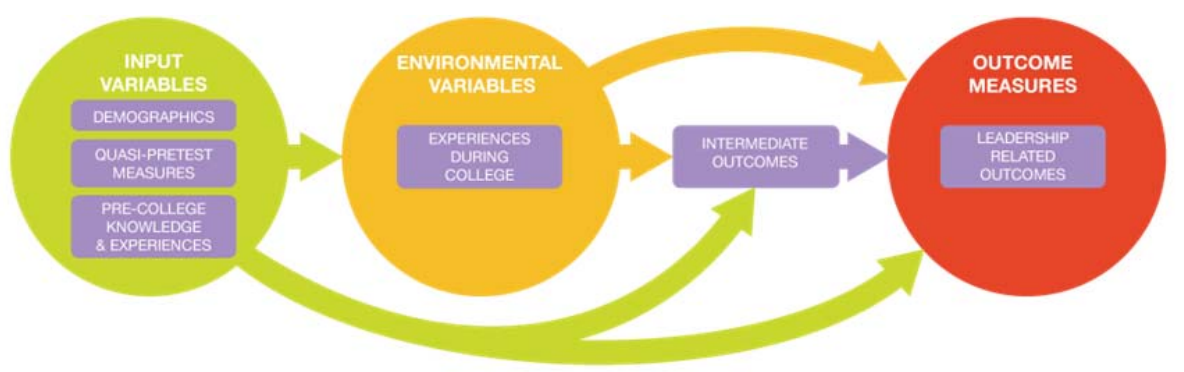

Source: Multi-Institutional Study of Leadership, 2012

The design of the MSL affords several benefits for this study. First, the MSL measures self-reported self-efficacies of leadership pre- and postcollegiate enrollment and leadership development via the social change model. This provides understanding of whether the host college environment impacts leadership self-efficacies of international students. Given the research questions in this study, the MSL captures demographic and environmental characteristics that provide insight into college student leadership development for a student population that few have focused on. The multi-institutional design approach supports the ability to disaggregate while generalizing the findings to understand the trends across various types of institutions. Since the MSL is one of the only multi-institutional studies of student leadership, it is an appropriate instrument for this kind of study to examine the experiences of international students nationally.

\section{Research Question}

In this study I asked if there is a difference between the leadership self-efficacy of domestic students and international students. Through this research question, I used a comparative, cross-sectional analysis of the students' leadership self-efficacy prior to and during their study in the U.S. as an international student. Since efficacy is fluid and is influenced by environmental factors that may either leverage or constrain an individual's perceptions of his or her capacity for leadership (Bandura, 1997), it is expected that the leadership self-efficacy of domestic students will differ from their international student peers. While it is expected that the 
leadership self-efficacy between domestic and international students will be different since these two student populations have vastly different experiences and challenges, research has not examined the magnitude of this difference.

\section{Sample}

Data for this study was obtained from the MSL and financially supported by the Indiana University Graduate School. The MSL research team recruited respondents from 82 registered institutions of higher education in the United States and the countries of Mexico, Canada, and West Indies, and it was administered by the Survey Science Group (SSG) between the months of January and April. The data were collected through the internet using a web-based administration of the MSL Student Survey (MSL-SS). Emails were sent to ask students to participate. Participants were drawn from student samples that depended on the size of institutional enrollment. Campuses that had an enrollment of 4,000 or less used the entire student population as their sample, while those with enrollments exceeding 4,000 drew a random sample standardized at $95 \%$ confidence interval with a $+/-3 \%$ confidence of error.

\section{Table 1: 2012 MSL Question 33}

\begin{tabular}{|c|c|c|}
\hline Variable & Variable label & Response coding \\
\hline DEM9 & $\begin{array}{l}\text { Indicate your } \\
\text { citizenship and/or } \\
\text { generational status: } \\
\text { (Choose One) }\end{array}$ & $\begin{array}{l}1=\text { Your grandparents, parents, } \\
\text { and you were born in the U.S. } \\
2=\text { Both of your parents AND } \\
\text { you were born in the U.S. } \\
3=\text { You were born in the U.S., } \\
\text { but at least one of your parents } \\
\text { was not } \\
4=\text { You are a foreign born, } \\
\text { naturalized citizen } \\
5=\text { You are a foreign born, } \\
\text { resident alien/permanent } \\
\text { resident } \\
6=\text { International student }\end{array}$ \\
\hline
\end{tabular}

At these institutions, student participants were oversampled by $70 \%$ in order to achieve at least a $30 \%$ response rate of the survey instrument in order to fall within the acceptable rate of $30-40 \%$ expected from internet survey data 
Table 2: Domestic and International Student Demographics

\begin{tabular}{|c|c|c|c|c|}
\hline \multirow[b]{2}{*}{ Variable } & \multicolumn{2}{|c|}{$\begin{array}{l}\text { Domestic } \\
\text { students }\end{array}$} & \multicolumn{2}{|c|}{$\begin{array}{c}\text { International } \\
\text { students }\end{array}$} \\
\hline & n & $\%$ & $\mathbf{n}$ & $\%$ \\
\hline \multicolumn{5}{|l|}{ Gender } \\
\hline Female & 47,246 & $63.2 \%$ & 1,679 & $49.0 \%$ \\
\hline Male & 27,292 & $36.5 \%$ & 1,742 & $50.8 \%$ \\
\hline Transgender & 138 & $0.3 \%$ & 9 & $0.2 \%$ \\
\hline \multicolumn{5}{|l|}{ Race } \\
\hline White/Caucasian & 55,316 & $74.0 \%$ & 432 & $12.6 \%$ \\
\hline Middle Eastern & 458 & $0.6 \%$ & 177 & $5.2 \%$ \\
\hline African American/Black & 3,226 & $4.3 \%$ & 169 & $4.9 \%$ \\
\hline American Indian/Alaska & & & & \\
\hline Native & 118 & $0.2 \%$ & 1 & $0.0 \%$ \\
\hline Asian American/Asian & 4,377 & $5.9 \%$ & 1,844 & $53.8 \%$ \\
\hline Latino/Hispanic & 3,759 & $5.0 \%$ & 282 & $8.2 \%$ \\
\hline Multiracial & 6,698 & $9.0 \%$ & 226 & $6.6 \%$ \\
\hline Race not included above & 764 & $1.0 \%$ & 299 & $8.7 \%$ \\
\hline \multicolumn{5}{|l|}{ Grade Point Average } \\
\hline $3.50-4.00$ & 31,147 & $41.7 \%$ & 1,545 & $45.0 \%$ \\
\hline $3.00-3.49$ & 27,934 & $37.4 \%$ & 1,180 & $34.4 \%$ \\
\hline $2.50-2.99$ & 11,996 & $16.1 \%$ & 496 & $14.5 \%$ \\
\hline $2.00-2.49$ & 2,762 & $3.7 \%$ & 119 & $3.5 \%$ \\
\hline 1.99 or less & 543 & $0.7 \%$ & 32 & $0.9 \%$ \\
\hline No college GPA & 199 & $0.3 \%$ & 48 & $1.4 \%$ \\
\hline \multicolumn{5}{|l|}{ Major } \\
\hline \multicolumn{5}{|l|}{$\begin{array}{l}\text { Science, Technology, } \\
\text { Engineering, and }\end{array}$} \\
\hline Mathematics & 16,301 & $21.8 \%$ & 1,123 & $32.8 \%$ \\
\hline $\begin{array}{l}\text { Professional and Pre- } \\
\text { professional }\end{array}$ & 5,380 & $7.2 \%$ & 133 & $3.9 \%$ \\
\hline Humanities & 9,941 & $13.4 \%$ & 219 & $6.4 \%$ \\
\hline Business & 11,072 & $14.8 \%$ & 1,132 & $33.0 \%$ \\
\hline Communication & 4,361 & $5.8 \%$ & 123 & $3.6 \%$ \\
\hline Health-Related Fields & 8,184 & $11.0 \%$ & 96 & $2.8 \%$ \\
\hline Education & 5,028 & $6.7 \%$ & 90 & $2.6 \%$ \\
\hline Multi/Interdisciplinary & & & & \\
\hline Studies & 1,516 & $2.0 \%$ & 69 & $2.0 \%$ \\
\hline Social Sciences & 10,906 & $14.6 \%$ & 368 & $10.7 \%$ \\
\hline Undecided & 2,003 & $2.7 \%$ & 75 & $2.2 \%$ \\
\hline
\end{tabular}


Class Level

Freshman/First Year

Sophomore

Junior

Senior/Fourth year and

beyond

Graduate Student

Unclassified

Parent/Guardian Education

Less than HS diploma/GED

HS diploma/GED

Some college

Associates degree

Bachelor's degree

Master's degree

Doctorate or professional

degree

$\begin{array}{llll}16,031 & 21.5 \% & 829 & 24.2 \% \\ 16,374 & 21.9 \% & 760 & 22.2 \% \\ 18,812 & 25.2 \% & 832 & 24.3 \%\end{array}$

Do not know

$\begin{array}{cccc}22,062 & 29.5 \% & 915 & 26.7 \% \\ 890 & 1.2 \% & 60 & 1.7 \% \\ 544 & 0.7 \% & 33 & 1.0 \%\end{array}$

$\begin{array}{cccc}1,645 & 2.2 \% & 197 & 5.7 \% \\ 8,928 & 11.9 \% & 528 & 15.4 \% \\ 9,670 & 12.9 \% & 287 & 8.4 \% \\ 5,802 & 7.8 \% & 150 & 4.4 \% \\ 21,661 & 29.0 \% & 1,040 & 30.3 \% \\ 16,991 & 22.7 \% & 696 & 20.3 \% \\ & & & \\ 9,180 & 12.3 \% & 393 & 11.5 \% \\ 689 & 0.9 \% & 130 & 3.8 \%\end{array}$

Parent/Guardian Income

Less than $\$ 12,500$

$\$ 12,500$ - \$24,999

3,171

$4.2 \%$

376

$11.0 \%$

$\$ 25,000$ - \$39,999

4,005

$5.4 \%$

275

$8.0 \%$

5,277

$7.1 \%$

244

$7.1 \%$

$\$ 40,000$ - $\$ 54,999$

5,921

$7.9 \%$

238

$6.9 \%$

$\$ 55,000$ - $\$ 74,999$

8,297

$11.1 \%$

267

$7.8 \%$

$\$ 75,000$ - $\$ 99,999$

8,916

$11.9 \%$

178

$5.2 \%$

$\$ 100,000$ - \$149,999

10,872

$14.6 \%$

200

$5.8 \%$

$\$ 150,000$ - \$199,999

5,040

$6.7 \%$

122

$3.6 \%$

$\$ 200,000$ and over

7,061

$9.5 \%$

268

$7.8 \%$

Do not know

11,107

$14.9 \%$

867

$25.3 \%$

Rather not say

4,846

$6.5 \%$

383

$11.2 \%$

collection (Crawford, Couper, \& Lamia, 2001). Students received up to four reminders within three weeks reminding them to participate. Once students entered the website, they were asked to enter their student identification number, which was separated from their email to provide confidentiality. The first question required consent from the student. If the student did not consent, the survey was closed immediately.

The 2012 MSL sample consisted of 91,178 study participants. There was a $33 \%$ response rate from a total of 276,297 students who were sent surveys. For this study, this response rate is acceptable as there are no other multi-institutional surveys with higher response rates. In addition, 
scholars in the field of higher education and student affairs have also accepted this rate to be acceptable since this dataset has been used for other published studies. Since this study is specifically examining international students, those that disclosed and identified their citizenship and/or generational status were chosen as the study participants. From the students who responded to the survey, only 78,146 students responded to the question pertaining to their citizenship and generational status (See Table 1). Given the research question, participants that identified as international students were selected for comparison with their domestic student peers in this analysis. A total of 3,430 international students were identified. The remaining students were classified as domestic students and used as a comparison group. Sample sizes were balanced to avoid violations of statistical assumptions in latter inquiry (Tabachnick \& Fidell, 2007). Table 2 describes the characteristics of the two subsamples student populations of domestic $(n=74,713)$ and international students $(n=3,430)$.

\section{Independent Variables}

\section{Input variables}

Independent input variables included the student's demographic characteristics, experiences prior to college (i.e., involvement in student organizations, leadership positions in student organizations, etc.), and quasipretest for leadership self-efficacy prior to college.

\section{Table 3: Leadership self-efficacy pre-test scale; 2012 MSL Question 9}

\begin{tabular}{|c|c|c|}
\hline Variable & Variable label & Response coding \\
\hline \multicolumn{2}{|c|}{$\begin{array}{l}\text { Looking back to before you started college, how } \\
\text { confident were you that you would be successful } \\
\text { in college at the following: (Select one response } \\
\text { for each) }\end{array}$} & \multirow{5}{*}{$\begin{array}{l}1=\text { Not at all } \\
\text { confident } \\
2=\text { Somewhat } \\
\text { confident } \\
3=\text { Confident } \\
4=\text { Very confident }\end{array}$} \\
\hline PRE2a & Leading others & \\
\hline PRE2b & $\begin{array}{l}\text { Organizing a group's } \\
\text { tasks to accomplish a } \\
\text { goal }\end{array}$ & \\
\hline PRE2c & $\begin{array}{l}\text { Taking initiative to } \\
\text { improve something }\end{array}$ & \\
\hline PRE2d & $\begin{array}{l}\text { Working with a team } \\
\text { on a group project }\end{array}$ & \\
\hline
\end{tabular}

The demographic characteristics chosen for this study included, but were not limited to, the student's racial group, ethnic group, gender, and area of 
study. Input measures that described pre-collegiate experiences were measured by responding to questions that involved engagement in cocurricular activities and community service by using a Likert scale from $0=$ Never to $3=$ Very often. A sample of activities asked about student engagement in student clubs and organizations, organized sports, leadership positions in student clubs, groups, or sports, community or work-related organizations, and training or education that developed leadership skills.

The student's perceptions of leadership self-efficacy prior to college were measured with a composite variable that included a quasi-pre-test of four self-reported individual items where students rated their confidence using a Likert scale of $1=$ Not at all confident to $4=$ Very confident. Students self-reported on their pre-college confidence in: leading others, organizing a group's tasks to accomplish a goal, taking initiative to improve something, and working with a team on a group project (Table 3 ).

In order to determine the students' pre-collegiate leadership selfefficacy, I conducted a principal component analysis (PCA) to capture the variation of the above variables PRE2a, PRE2 $b$, PRE2c, and PRE2d and reduce them down to the variable LSEpre. The Cronbach's alpha level for this scale, which indicates the scale's internal consistency, was found to be 0.87 for the entire student population (Dugan, Kodama, \& Gebhardt, 2012; Dugan \& Komives, 2010; Komives, Wagner \& Associates, 2009). In order to confirm this level, I conducted my own analysis for all students surveyed.

\section{Environmental variables}

The environmental variables in this study included their class standing and institutional characteristics, including institutional size, control, and Carnegie classification. The other variables included student involvement experiences, such as membership in student organizations, onand off-campus organizations, leadership positions in student organizations, community service, participation in formal leadership programs, mentoring relationships, on- and off-campus employment, sense-of-belonging, and discriminatory climate. Distributions for all environmental variables were examined for accuracy and normality distribution through histograms and all were unimodal.

\section{Dependent Variables}

\section{Outcome variable}

Since the purpose of this study was to examine how collegiate environments affect the educational outcome of leadership self-efficacy, the dependent variable in this study is the leadership self-efficacy post-test, which also served as the education outcome variable in Astin's IEO college impact conceptual model. It was a composite measure that asked 
individuals to self-report how confident they were in leading others, organizing a group's tasks to accomplish a goal, taking initiative to improve something, and working with a team on a group project. Responses were reported using an identical scale as the quasi-pre-test of $1=$ Not at all confident to $4=$ Very confident.

\section{Table 4: 2012 MSL Question 24: Leadership Self-Efficacy Post-Test Scale}

\begin{tabular}{|c|c|c|}
\hline Variable & Variable label & Response coding \\
\hline OUT2a & Leading others & $1=$ Not at all confident \\
\hline OUT2b & $\begin{array}{l}\text { Organizing a group's tasks to } \\
\text { accomplish a goal }\end{array}$ & $2=$ Somewhat confident \\
\hline OUT2c & $\begin{array}{l}\text { Taking initiative to improve } \\
\text { something }\end{array}$ & $3=$ Confident \\
\hline OUT2d & $\begin{array}{l}\text { Working with a team on a } \\
\text { group project }\end{array}$ & $4=$ Very confident \\
\hline
\end{tabular}

It is important to note that in this post-test, students rated their efficacy of leadership at the time of taking the survey. Similar to the leadership self-efficacy pre-test, I conducted a principal component analysis to create the variable LSEpost by merging the responses to the four survey questions OUT2a, OUT2b, OUT2c, OUT2d. A separate analysis confirmed the reported Cronbach's alpha of 0.87 for internal consistency of the scale (Dugan, Kodama, \& Gebhardt, 2012; Dugan \& Komives, 2010; Komives, Wagner \& Associates, 2009). Similar to the leadership self-efficacy pretest, to confirm that the internal consistency of the post-test scale was just as reliable separately for international students and domestic students, I conducted a Cronbach's Alpha analysis of the leadership self-efficacy posttest scale for both the international student and domestic student population separately. For the international student subgroup, the reliability was similar and just as consistent as the total student population. For the domestic student population, the reliability of the scale was also similar and consistent. Distributions for all outcome variables were examined for accuracy and normality distribution through histograms and all were unimodal.

\section{Data Analysis}

The data analysis included several different statistical procedures to determine whether the host campus environment was a determining factor in international students' self-efficacy of leadership and whether there were differences in their leadership efficacy between the international and domestic student population. Prior to analysis, the assumptions of linearity 
and absence of multicollinearity were examined by running scatterplots and correlations. The scatterplots revealed no evidence of nonlinear relationships between the variables. Then, I screened the data for errors by examining the descriptive statistics of each variable to confirm that the data fell within the acceptable range and that the variables in the regression model did not violate statistical assumptions related to multicollinearity (Cohen, Cohen, West, \& Aiken, 2003; Tabachnick \& Fidell, 2007).

\section{Regression model}

Using a multiple regression analysis using ordinary least squares regression, the following regression equation was used to determine the differences between their leadership self-efficacy prior to attending college:

$\mathrm{LSE}_{\mathrm{PRE}}=\beta_{0}+\beta_{1} \mathrm{INTL} \_\mathrm{DUM}+\beta_{2}[\mathrm{DEMO}]+\varepsilon$,

where $L_{S E_{P R E}}$ is the leadership self-efficacy pre-test rating; INTL_DUM is a dummy variable indicating $1=$ international students and $0=$ domestic students; DEMO is a vector comprising of student demographics, which included class level, primary major, gender, race, GPA, parent/guardian level of education, and parent/guardian household income; and $\varepsilon$ is the error term.

In order to determine if the differences in leadership self-efficacy of domestic students and international students are impacted by the collegiate environment, a multiple regression analysis was conducted on the leadership self-efficacy pre-test of international students and domestic students. Using a multiple regression analysis using ordinary least squares regression, the following regression equation was used to determine how the college environment impacted the students' leadership self-efficacy:

\section{$\mathrm{LSE}_{\mathrm{POST}}=\beta_{0}+\beta_{1} \mathrm{LSE}_{\mathrm{PRE}}+\beta_{2} \mathrm{INTL} \mathrm{DUM}+\beta_{3}[\mathrm{DEMO}]+\varepsilon$,}

where $\mathrm{LSE}_{\mathrm{POST}}$ is the leadership self-efficacy post-test rating; $\mathrm{LSE}_{\mathrm{PRE}}$ is the leadership self-efficacy pre-test rating; INTL_DUM is a dummy variable indicating $1=$ international students and $0=$ domestic students; DEMO is a vector comprising of student demographics, which included class level, primary major, gender, race, GPA, parent/guardian level of education, and parent/guardian household income; and $\varepsilon$ is the error term.

\section{RESULTS}

\section{Examining differences in leadership self-efficacy prior to college}

Multiple models were used to analyze the impact of the student demographics as control variables. In order to determine which demographic control trait had a larger effect than the student's international status, multiple regression analyses were employed that included different covariates and the resulting models were analyzed. The results of these models are presented below. In the resulting regression model, which 
included two interaction terms, the international student $\mathrm{LSE}_{\text {pre }}$ was significant at a $\mathrm{p}<0.10$ level.

After all of the student demographics were incorporated, the effect of the international students' $\mathrm{LSE}_{\text {pre }}$ decreased but was still significant at a $\mathrm{p}$ $<0.10$ level $\left(\mathrm{LSE}_{\mathrm{pre}}=-0.024\right)$. Overall, international students had lower $\mathrm{LSE}_{\text {pre }}$ than their domestic student peers. While the students' racial group had an impact, it was not as important as their academic major. Only African American/Black, Asian American/Asian, and race not included students had significant $\mathrm{LSE}_{\text {pre }}$ scores. For African American/Black students, after accounting for academic major, class standing, and class GPA, their $\mathrm{LSE}_{\text {pre }}$ score increased from $\beta=0.052$ to $\beta=0.064$. Their LSE was higher than the reference racial group, White/Caucasian students. Asian American/Asian students had the lowest $\mathrm{LSE}_{\text {pre }}$ scores than any other racial group.

Academic major had the largest effect on a students' LSE $_{\text {pre. }}$ With business majors as a reference, all other academic majors reported lower $\mathrm{LSE}_{\text {pre. }}$ Students with undecided majors reported significantly lower LSE scores than any other majors $(\beta=-0.259, \mathrm{p}<0.001)$. Students majoring in the humanities $(\beta=-0.172, p<0.001)$, science, technology, engineering, and mathematics (STEM) $(\beta=-0.128, p<0.001)$, and social sciences $(\beta=$ $0.122, \mathrm{p}<0.001)$ had some of the lowest $\mathrm{LSE}_{\text {pre. }}$ Although lower than the business major peers, professional/pre-professional $(\beta=-0.034, p<0.001)$, education $(\beta=-0.069, \mathrm{p}<0.001)$, and multi/interdisciplinary studies $(\beta=$ $0.080, \mathrm{p}<0.001)$ students reported some of the higher $\mathrm{LSE}_{\mathrm{pre}}$.

\section{Examining differences in leadership self-efficacy after attending college}

The purpose of this study was to examine whether students' leadership self-efficacy was impacted by their college environments (LSE $E_{\text {post }}$ ). More particularly, the study compared the outcome for international students against their domestic student peers. After including all student demographics as covariates and the $\mathrm{LSE}_{\text {pre, }}$ international students reported a much lower $\operatorname{LSE}_{\text {post }}$ than their domestic student peers $(\beta=-0.127$, $\mathrm{p}=0.001)$.

The regression model showed a significant difference between the $\mathrm{LSE}_{\text {post }}$ of international students compared to domestic students. International students scored lower on average $(\beta=-0.127, \mathrm{p}<.001)$ on the $\mathrm{LSE}_{\text {post }}$ compared to their domestic student peers after all of the student demographics and $\mathrm{LSE}_{\text {pre }}$ were incorporated in Model 6. Demographic variables (race, academic major, gender, class standing, college GPA) were also not found to have a large influence except for the students' academic major. Students' majors were found to have a relatively similar effect on students' $\mathrm{LSE}_{\text {post }}$ compared to students' international/domestic status. 
Journal of International Students, 6(4) 2016

Table 5: LSEpre with student demographics

\begin{tabular}{lllllll}
\hline & Model 1 & Model 2 & Model 3 & Model 4 & Model 5 & Model 6 \\
Variables & & & & & & \\
\hline Int'l student leader- & $-0.057^{* * *}$ & $-0.069 * * *$ & -0.004 & -0.023 & $-0.024^{*}$ & $-0.024^{*}$ \\
ship self-efficacy & $(0.013)$ & $(0.013)$ & $(0.014)$ & $(0.014)$ & $(0.014)$ & $(0.014)$ \\
pre-test score & & & & & &
\end{tabular}

Gender

Male*

Female

Transgender

$\begin{array}{ccccc}- & - & - & - & - \\ -.086 * * * & -.083 * * * & -.063 * * * & -.064 * * * & -.068 * * * \\ (0.005) & (0.008) & (0.008) & (0.008) & (0.013) \\ -.324 * * * & -.328 * * * & -.267 * * * & -.267 * * * & -.270 * * * \\ (0.059) & (0.061) & (0.061) & (0.061) & (0.065)\end{array}$

Race

White/Caucasian*

Middle Eastern

African Ameri-

can/Black

American Indi-

an/Alaska Native

Asian Ameri-

can/Asian

Latino/Hispanic

Multiracial

Race not included

$\begin{array}{cccc}- & - & - & - \\ 0.015 & 0.022 & 0.022 & 0.023 \\ (0.029) & (0.029) & (0.029) & (0.029) \\ 0.052 * * * & 0.062 * * * & 0.062 * * * & 0.064 * * * \\ (0.015) & (0.015) & (0.015) & (0.015) \\ 0.098 & 0.109 & 0.106 & 0.108 \\ (0.067) & (0.067) & (0.067) & (0.067) \\ -.131 * * * & -.128 * * * & -.129 * * * & -.127 * * * \\ (0.018) & (0.018) & (0.018) & (0.018) \\ -0.022 & -0.008 & -0.01 & -0.008 \\ (0.022) & (0.022) & (0.022) & (0.022) \\ 0.01 & 0.025 & 0.024 & 0.026 \\ (0.025) & (0.025) & (0.025) & (0.025) \\ 0.064 * & 0.080 * * & 0.080 * * & 0.083 * * \\ (0.035) & (0.035) & (0.035) & (0.035)\end{array}$

Academic major

Business*

STEM

Professional/pre-

professional

Humanities

Communication

Health-related

fields

Education

Interdisciplinary

studies

Social sciences

$\begin{array}{ccc}-.129 * * * & -.129 * * * & -.128 * * * \\ (0.008) & (0.008) & (0.008) \\ -.033 * * * & -.034 * * * & -.034 * * * \\ (0.012) & (0.012) & (0.012) \\ -.175 * * * & -.173 * * * & -.172 * * * \\ (0.010) & (0.010) & (0.010) \\ -0.02 & -0.018 & -0.018 \\ (0.013) & (0.013) & (0.013) \\ -.096 * * * & -.097 * * * & -.097 * * * \\ (0.010) & (0.010) & (0.010) \\ -.067 * * * & -.070 * * * & -.069 * * * \\ (0.012) & (0.012) & (0.012) \\ -.083 * * * & -.081 * * * & -.080 * * * \\ (0.019) & (0.019) & (0.019) \\ -.124 * * * & -.123 * * * & -.122 * * * \\ (0.009) & (0.009) & (0.009) \\ -.251 * * * & -.261 * * * & -.259 * * * \\ (0.017) & (0.017) & (0.017)\end{array}$

Undecided

Class standing

Freshman/First-

year*

Sophomore

$-0.007 \quad-0.008$

Junior

(0.008) (0.008)

$-.019 * * \quad-.020 * * *$ 
Senior/Fourth-year

\& beyond

Graduate

Unclassified

College GPA

$3.50-4.00 *$

$3.49-3.00$

$2.99-2.50$

$2.49-2.00$

1.99 or less

No college GPA

Interactions

Gender* Race

Gender * Major

Constant

Adj. R-squared

$\begin{array}{cc}(0.008) & (0.008) \\ -.023 * * * & -.025 * * * \\ (0.007) & (0.007) \\ 0.089 * * * & 0.090 * * * \\ (0.024) & (0.024) \\ 0.012 & 0.01 \\ (0.030) & (0.030)\end{array}$

$\begin{array}{cccc}-0.002 & -0.002 & -0.002 & -0.002 \\ (0.002) & (0.002) & (0.002) & (0.002) \\ & -.010 * * * & -.010 * * * & -.008 \\ & (0.002) & (0.002) & (0.006) \\ & & & \\ 2.918 * * * & 3.031 * * * & 3.043 * * * & 3.035 * * * \\ (0.005) & (0.008) & (0.010) & (0.010) \\ 0.007 & 0.015 & 0.015 & 0.015\end{array}$

Notes: $N=78,093$ students.

$* p<0.10$

$* * p<0.05$

$* * * p<0.01$

\section{Comparing the differences between $L_{S E}$ pre \& $L_{S E}$ post}

Comparing the differences between the $\mathrm{LSE}_{\text {pre }}$ and $\mathrm{LSE}_{\text {post }}$ provided for interesting analysis. While the $\mathrm{LSE}_{\text {pre }}$ analysis had other unobservable factors that were not accounted for in the model, which resulted in a small $\mathrm{R}$-squared and low variability in the model, a comparison between the variables can explain the differences of $\mathrm{LSE}_{\text {pre }}$ and $\mathrm{LSE}_{\text {post }}$ for the various student characteristics. While domestic students were expected to increase their leadership self-efficacy after attending college, this conclusion cannot be drawn from these models as the $\mathrm{LSE}_{\text {pre }}$ model explained very little variation $(\mathrm{R}$-squared $=0.015)$ compared to the $\mathrm{LSE}_{\text {post }}$ model $(\mathrm{R}$-squared $=$ 0.308). However, while comparing the leadership self-efficacy of students generally, international students' leadership self-efficacy developed less over time during college compared to their domestic student peers. A 
comprehensive comparison between $\mathrm{LSE}_{\text {pre }}$ and $\mathrm{LSE}_{\text {post }}$ of the significant variables is reported below.

\section{Table 6: LSEpost with student demographics}

\begin{tabular}{lcccccc}
\hline Variables & Model 1 & Model 2 & Model 3 & Model 4 & Model 5 & Model 6 \\
\hline $\begin{array}{l}\text { International } \\
\text { student }\end{array}$ & $-.186^{* * *}$ & $-.187^{* * *}$ & $-.113^{* * *}$ & $-.131^{* * *}$ & $-.125^{* * *}$ & $-.127^{* * *}$ \\
$\quad(0.010)$ & $(0.010)$ & $(0.011)$ & $(0.011)$ & $(0.011)$ & $(0.011)$ \\
$\quad \begin{array}{l}\text { leadership self- } \\
\text { efficacy post-test }\end{array}$ & & & & & & \\
score & & & & & & \\
& & & & & & \\
International & $0.465^{* * *}$ & $0.464^{* * *}$ & $0.461^{* * *}$ & $0.454^{* * *}$ & $0.456^{* * *}$ & $0.456^{* * *}$ \\
student & $(0.003)$ & $(0.003)$ & $(0.003)$ & $(0.003)$ & $(0.003)$ & $(0.003)$ \\
$\quad$ leadership self- & & & & & & \\
efficacy pre-test & & & & & & \\
score & & & & & & \\
Gender & & & & & & \\
Male* & & - & - & - & - & - \\
Female & & $-0.009^{* *}$ & 0.001 & $0.042^{* * *}$ & $0.041^{* * *}$ & 0.007 \\
Transgender & $(0.004)$ & $(0.006)$ & $(0.006)$ & $(0.006)$ & $(0.010)$ \\
& & $-.231^{* * *}$ & $-.211^{* * *}$ & $-.083^{*}$ & $-.098^{* *}$ & $-.171^{* * *}$ \\
& & $(0.046)$ & $(0.047)$ & $(0.047)$ & $(0.047)$ & $(0.049)$
\end{tabular}

Race

White/Caucasia*

Middle Eastern

African

American/Black

American

Indian/Alaska

Native

Asian

American/Asian

Latino

Multiracial

Race not

included

$\begin{array}{cccc}- & - & - & - \\ -0.005 & 0.011 & 0.005 & 0.007 \\ (0.023) & (0.022) & (0.022) & (0.022) \\ 0.056^{* * *} & 0.086^{* * *} & 0.082^{* * *} & 0.086^{* * *} \\ (0.012) & (0.012) & (0.011) & (0.011) \\ 0.038 & 0.058 & 0.051 & 0.056 \\ (0.052) & (0.051) & (0.051) & (0.051) \\ & & & \\ -.123^{* * *} & -.124^{* * *} & -.119^{* * *} & -.116^{* * *} \\ (0.014) & (0.014) & (0.014) & (0.014) \\ 0.037 * * & 0.048^{* * *} & 0.046^{* * *} & 0.053^{* * *} \\ (0.017) & (0.017) & (0.017) & (0.017) \\ 0.034 * & 0.033^{*} & 0.040^{* *} & 0.047 * * \\ (0.019) & (0.019) & (0.019) & (0.019) \\ 0.031 & 0.034 & 0.031 & 0.039 \\ (0.027) & (0.027) & (0.026) & (0.026)\end{array}$

Academic major

Business*

STEM

Professional/pre-

professional

Humanities

$\begin{array}{ccc}-.106 * * * & -.096 * * * & -.097 * * * \\ (0.007) & (0.006) & (0.006) \\ -.065 * * * & -.043^{* * *} & -.043 * * * \\ (0.009) & (0.009) & (0.009) \\ -.094 * * * & -.099 * * * & -.099 * * * \\ (0.008) & (0.007) & (0.007) \\ -0.002 & -0.003 & -0.002 \\ (0.010) & (0.010) & (0.010) \\ -.080^{* * *} & -.077 * * * & -.077 * * * \\ (0.008) & (0.008) & (0.008)\end{array}$

fields

Communication

Health-related 
Education

Interdisciplinary

studies

Social sciences

Undecided

Class standing

Freshman/First-

year*

Sophomore

Junior

Senior/Fourthyear \& beyond

Graduate

Unclassified

College GPA

$3.50-4.00 *$

$3.49-3.00$

$2.99-2.50$

$2.49-2.00$

1.99 or less

No college GPA

Interactions

Gender* Race

Gender * Major

\section{Constant}

Adj. R-squared

$\begin{array}{ccc}-.021 * * & -.027 * * * & -.026 * * * \\ (0.009) & (0.009) & (0.009) \\ -.063 * * * & -.066 * * * & -.066 * * * \\ (0.015) & (0.015) & (0.015) \\ -.053 * * * & -.062 * * * & -.062 * * * \\ (0.007) & (0.007) & (0.007) \\ -.319 * * * & -.198 * * * & -.197 * * * \\ (0.013) & (0.013) & (0.013)\end{array}$

$\begin{array}{cc}0.082 * * * & 0.083 * * * \\ (0.006) & (0.006) \\ 0.171 * * * & 0.172 * * * \\ (0.006) & (0.006) \\ 0.267 * * * & 0.268 * * * \\ (0.006) & (0.006) \\ 0.227 * * * & 0.228 * * * \\ (0.018) & (0.018) \\ 0.143 * * * & 0.142 * * * \\ (0.023) & (0.023)\end{array}$

$.024 * * *$

(0.009)

$-.070 * * *$

(0.015)

$-.110 * * *$

(0.023)

$-.167 * * *$

(0.036)

0.007

(0.050)

$\begin{array}{cccc}-0.005 * * * & -0.003 & -0.003 & -0.004 * * \\ (0.002) & (0.002) & (0.002) & (0.002) \\ & -.031 * * * & -.028 * * * & -.010 * * \\ & (0.001) & (0.001) & (0.004)\end{array}$

$\begin{array}{cccccc}1.823 * * * & 1.831 * * * & 1.850 * * * & 1.995 * * * & 1.834 * * * & 1.828 * * * \\ (0.008) & (0.009) & (0.009) & (0.010) & (0.011) & (0.011) \\ 0.267 & 0.268 & 0.271 & 0.284 & 0.307 & 0.308\end{array}$

Notes: $N=78,093$ students.

$$
\begin{aligned}
& * p<0.10 \\
& * * p<0.05 \\
& * * * p<0.01
\end{aligned}
$$


Table 7: Comparison between LSEpre \& LSEpost

\begin{tabular}{lll}
\hline Variables & LSE $_{\text {pre }}$ & LSE $_{\text {post }}$ \\
\hline
\end{tabular}

International student

leadership self-efficacy

score

$-0.024 *$

$-0.127^{* * *}$

(0.014)

(0.011)

Gender

Male*

Female

$-0.064 * * *$

$0.041 * *$

(0.008)

$(0.006)$

Transgender

$-0.270 * * *$

(0.065)

$-0.171^{* * *}$

(0.049)

Race

White*

African American/Black

$0.064 * * *$

(0.015)

$0.086^{* * * *}$

$-0.127 * * *$

$(0.011)$

Asian American/Asian

(0.018)

$-0.116^{* * *}$

(0.014)

Academic major

Business*

STEM

$-0.128 * * *$

(0.008)

$-0.097 * * *$

Professional/pre-

$-0.034 * * *$

(0.006)

professional

(0.012)

$-0.043 * * *$

Humanities

$-0.172 * * *$

(0.009)

(0.010)

$-0.099 * * *$

Health-related fields

$-0.097 * * *$

$(0.007)$

(0.010)

$-0.077 * * *$

Education

$-0.069 * * *$

(0.008)

(0.012)

$-0.026^{* * *}$

Multi/Interdisciplinary

$-0.080 * * *$

(0.009)

studies

(0.019)

$-0.066^{* * *}$

(0.015) 


$\begin{array}{lcc}\text { Social sciences } & -0.122 * * * & -0.062 * * * \\ & (0.009) & (0.007) \\ \text { Undecided } & -0.259 * * * & -0.197 * * * \\ & (0.017) & (0.013)\end{array}$

\section{Class standing}

Freshman/First-year*

Junior

$-0.020 * * *$

$0.172 * * *$

(0.008)

(0.006)

Senior/Fourth-year \&

$0.025 * * *$

$0.268 * * *$

beyond

(0.007)

(0.006)

Graduate

$0.090 * * *$

(0.024)

$0.228 * * *$

(0.018)

$3.035 * * *$

$1.828 * * *$

Constant

(0.010)

(0.011)

Adj. R-squared

0.015

0.308

Notes: $N=78,093$ students.

$* p<0.10$

$* * p<0.05$

$* * * p<0.01$

(1) Model 5 used for the female variable

\section{LIMITATIONS}

Common to any research study, there were limitations to this study. First, the MSL survey was developed primarily for domestic students. As a result, many of the survey questions could be misinterpreted or misunderstood by international students. For example, questions regarding pre-collegiate experiences asking students to respond to participation in specific high school activities may not apply to international students. Many countries do not have high school varsity sports, nor do they have after-school extracurricular activities. Questions that do not have the same application to international students as domestic students, such as study abroad, could confuse student respondents to answer inaccurately. Also, because of the overrepresentation of domestic students, after disaggregating the data to analyze only the international students, often times results were not significant to permit conclusions to be made because of the small number of 
responses. For example, in this study racial/ethnic background variables were collapsed and recoded. Although this practice is typical for higher education studies, it perpetuates an underrepresentation and marginalization of students, contributing to the lack of understanding of their unique needs.

Another limitation was a result of relatively small number of responses from international students. Although the number of international student was sufficient for statistical comparisons with domestic counterparts (i.e. 3,430 students), there was not enough to conduct a within group analysis to examine each ethnic group. Because of the large number of domestic students compared to the relatively small number of international students, this caused an issue of power resulting in poor-model fits and low power issues when analyzing these two student groups. In addition, unobservable factors in the $\mathrm{LSE}_{\text {pre }}$ analysis resulted in a significant model but low variability. As a result, factors that were not accounted for resulted in a higher constant compared to the $\mathrm{LSE}_{\text {post }}$ model that explained more variation. In addition, given the $33 \%$ response rate, there may be potential biases that affected the study's interpretations of results. Since students self-reported their immigration status, this was an uncontrolled and potentially confounding variable. However, these aside, the data provided important data for comparison.

Despite these limitations, the study remains useful as it provides valuable information about leadership efficacy of international students. This study, despite its limitations also calls for more research on this important topic, including qualitative research. While previous studies have examined leadership-related issues of students, none have examined the growing population of international students. Given that the survey was originally targeted for domestic students, although it poses limitations for this study, the data allowed for valuable observations of international students on American host campuses.

\section{DISCUSSION}

The majority of research on leadership self-efficacy to date has not distinguished international students from the domestic counterparts (Spencer-Rodgers, 2001). Because of the increasing importance of international students on campus, it is critical to understand how international students compare to their domestic peers in their sense of leadership self-efficacy, which is a critical college outcome (Astin \& Astin, 2000). This study indicated that international students have smaller gains in leadership self-efficacy than their domestic peers. The largest significant difference between domestic and international students was observed in the leadership self-efficacy post-test, which reported the students' confidences in their leadership capacity after some college or college graduation. Given 
that higher education has taken upon itself the responsibility to prepare and develop future generations of domestic and international students (Astin \& Astin, 2000; Zimmerman-Oster \& Burkhart, 1999), this finding suggests that the experience for international students contrasts with their domestic peers.

When international students responded to the LSE pre-test, their scores were only slightly lower than their domestic peers after the regression analyses were included and controlled for student demographics. Given that the LSE pre-test asked students to reflect on their experiences prior to attending college, it would appear that the variance between domestic and international students' LSE pre-test may be a result of cultural differences and differing leadership opportunities prior to attending college. If the college experience impacted domestic and international students equally, the difference between the LSE pre-test and post-test for domestic and international students would be similar in magnitude (see Table 7). However, further exploration showed that while international students improved their leadership self-efficacy after graduation or attending some college, the magnitude of improvement was much smaller compared to their domestic peers. It would appear that the college environment does not shape leadership experiences equally for domestic and international students.

These findings supported literature that international students face challenges that impact their educational success on campus (Anderson, Carmichael, Harper, \& Huang, 2009; Dillard \& Chisolm, 1983; Mori, 2000; Owie, 1982; Schram \& Lauver, 1988; Tseng \& Newton, 2002; Yi, Lin, \& Kishimoto, 2003). While there are campus support services and programming for all students, these services and programs are not equally meeting the needs of international students (Kher, Juneau, \& Molstad, 2003). These results also raise the question as to whether institutions are investing enough resources for and staff and faculty time working with international students. These challenges can significantly impact their selfefficacy (Gloria \& Ho, 2003) as exhibited by these findings, and the personal belief of self-efficacy can change based on different factors of function based on self-efficacy, competency, and environment (McCormick, Tanguma, \& Lopez-Forment, 2002).

\section{IMPLICATIONS FOR PRACTICE AND CONCLUSIONS}

This study provides useful information and understanding of international student self-efficacy of leadership. The results presented and interpretations discussed have the following implications for research and practice in the field and profession of higher education. The results suggest that international students should not be treated as a homogenous group with 
their domestic student peers. While campus administrators and professionals open all programs and interventions to all students, including international students, these are not impactful for international students since they are domestic student-dominated and domestic student-centric and may not be sensitive to the cultural norms of other countries. College administrators should consider developing leadership training and education programs specifically for their international student population. In some instances, programs may also consider the students' racial and ethnic background, as students' ethnicity can impact their leadership experience and efficacy. This could be achieved by partnering with campus cultural centers or identity-based organizations. This study can be used to shape the nature of educational interventions and their points of delivery; for example, international programming can target specific international student subgroups for certain programs where they would be more likely to be effective rather than spreading resources widely across the entire student population. Student affairs professionals should also understand how certain programs and services would be more beneficial to certain subgroup populations while others have no interest in them.

Overall, many campuses expect that international students will take part in programming and activities available to all students on campus; however, administrators, faculty, and student affairs professionals do not realize that such an approach may alienate many students who are already struggling with the new academic system, cultural shock, language barriers, cultural differences, and instances of discrimination. This could prevent international students from positively engaging in opportunities around campus. The findings from this study suggest that more attention needs to be given to international students' engagement and development of leadership capacity on American host campuses.

In addition, the study findings provide a more accurate examination of the leadership development and efficacy of international students and academic and social adaptations of particular international student populations in the United States. Understanding unique student subcultures and how they impact outcomes is important to interpreting general college outcomes instead of simply measuring them (Renn \& Arnold, 2003). The theoretical implications of this study may influence future international student engagement, advocacy, recruitment, retention, alumni involvement, and engagement practices. It may also provide conceptual leads for the study of leadership development amongst international students in other countries outside of the United States.

\section{REFERENCES}

Anderson, G., Carmichael, K. Y., Harper, T. J., \& Huang, T. (2009). International students at four year institutions: Developmental needs, issues, and strategies. In S. R. Harper \& S. J. Quaye (Eds.), Student engagement in 
higher education: Theoretical perspectives and practical approaches for diverse populations (pp. 17-37). New York \& London: Routledge.

Andrade, M. (2006). International student perspective: Integration or cultural integrity? Journal of College Student Retention, 8(1), 57-81.

Astin, A. W. (1991). Assessment for excellence. New York, NY: American Council of Education/Macmillan.

Astin, A. W. (1993). What matters in college: Four critical years revisited. San Francisco: Jossey-Bass.

Astin, A. W., \& Astin, H. S. (Eds.). (2000). Leadership considered: Engaging higher education in social change. Battle Creek, MI: W.K. Kellogg Foundation.

Avolio, B.J. \& Gardner, W.L. (2005). Authentic leadership development: Getting to the roots of positive forms of leadership. The Leadership Quarterly, 16(3), 315-338.

Bandura, A. (1977). Self-efficacy: Toward a unifying theory of behavioral change. Psychological Review, 84(2), 191-215.

Bandura, A. (1997). Self-efficacy: The exercise of control. New York: Freeman.

Brodbeck, F. C., Frese, M., Akerblom, S., Audia, G., Bakacsi, G., Bendova, H., ... $\&$ Wunderer, R. (2000). Cultural variation of leadership prototypes across 22 European countries. Journal of occupational and organizational psychology, 73(1), 1-30.

Chemers, M. M. (2000). Leadership research and theory: A functional integration. Group Dynamics: Theory, Research and Practice, 4(1), 27-43.

Chhokar, J. S., Brodbeck, F. C., \& House, R. J. (Eds.). (2013). Culture and leadership across the world: The GLOBE book of in-depth studies of 25 societies. New York: Routledge.

Cohen, J., Cohen, P., West, S. G., \& Aiken, L. S. (2003). Applied Multiple Regression/Correlation Analysis for the Behavioral Sciences ( $3^{\text {rd }}$ Ed.). London: Routledge.

Crawford, S. D., Couper, M. P., \& Lamias, M. J. (2001). Web surveys: Perceptions of burden. Social Science Computer Review, 19(2), 146-162.

Day, D. V., Harrison, M. M., \& Halpin, S. M. (2009). An integrative approach to leader development. New York, NY: Routledge.

Dillard, J. M., \& Chisolm, G. B. (1983). Counseling the international students in a multicultural context. Journal of College Student Personnel, 24(2), 101105.

Dugan, J. P. (2011). Research on college student leadership. In S. R. Komives, J. P. Dugan, J. E. Owen, W. Wagner, \& C. Slack (Eds.), Handbook for student leadership development (pp.55-90). San Francisco: Jossey-Bass.

Dugan, J. P., Fath, K. Q., Howes, S. D., Lavelle, K. R., \& Polanin, J. (2013). Developing the leadership efficacy and leadership capacity of women in STEM majors. Journal of Leadership Studies, 7(3), 6-23.

Dugan, J. P., Garland, J. L., Jacoby, B., \& Gasiorski, A. (2008). Understanding commuter student self-efficacy for leadership: A within-group analysis. NASPA Journal, 45(2), 282-310.

Dugan, J. P., Kodama, C. M., \& Gebhardt, M. C. (2012). Race and leadership development among college students: The additive value of collective racial esteem. Journal of Diversity in Higher Education, 5(3), 174-189. 
Dugan, J. P., \& Komives, S. R. (2007). Developing leadership capacity in college students: Findings from a national study. A report from the MultiInstitutional Study of Leadership. College Park, MD: National Clearinghouse for Leadership Programs.

Dugan, J. P., \& Komives, S. R. (2010). Influences on college students' capacity for socially responsible leadership. Journal of College Student Development, 51(5), 525-549.

Dugan, J. P., Komives, S. R., \& Associates. (2006). Multi-Institutional Study of Leadership: A guidebook for participating campuses. College Park, MD: National Clearinghouse for Leadership Programs.

Gloria, A. M., \& Ho, T. A. (2003). Environmental, social, and psychological experiences of Asian American undergraduates: Examining issues of academic persistence. Journal of Counseling and Development, 81(1), 93105.

Groves, R. M., Fowler, F. J., Couper, M. P., Lepkowski, J. M., Singer, E., \& Tourangeau, R. (2004). Survey methodology. Wiley series in survey methodology. Hoboken, NJ: John Wiley \& Sons.

Hannah, S. T., Avolio, B. J., Luthans, F., \& Harms, P. D. (2008). Leadership efficacy: Review and future directions. Leadership Quarterly, 19(6), 669692.

Hofstede, G. (1980). Motivation, leadership, and organization: Do American theories apply abroad? Organizational dynamics, 9(1), 42-63.

Howard, G.S. (1980). Response shift bias: A problem in evaluating interventions with pre/post self-reports. Evaluation Review, 4(1), 93-106.

Howard, G. S., \& Dailey, P. R. (1979). Response-shift bias: A source of contamination in self-report measures. Journal of Applied Psychology, 64(2), 114-150.

Kher, N., Juneau, G., \& Molstad, S. (2003). From the southern hemisphere to the rural south: A Mauritian student's version of coming to America. College Student Journal, 37(4), 564-569.

Kodama, C., \& Dugan, J. P. (2013). Leveraging leadership efficacy in college students: Disaggregating data to examine unique predictors by race. Equity \& Excellent in Education, 46(2), 184-201.

Komives, S. R., \& Dugan, J. P. (2010). Contemporary leadership theories. In R.A. Couto (Ed.), The handbook of political and civil leadership (pp. 109-125). Thousand Oaks: CA: Sage.

Komives, S. R., Owen, J. O., Longerbeam, S. D., Mainella, F., \& Osteen, L. (2005). Developing a leadership identity: A grounded theory. Journal of College Student Development, 46(6), 593-611.

Komives, S.R., Wagner, W., \& Associates. (2009). Leadership for a better world: Understanding the social change model of leadership development. San Francisco: Jossey-Bass.

Leong, P. (2015). Coming to America: Assessing the patterns of acculturation, friendship formation, and the academic experiences of international students at a U.S. college. Journal of International Students, 5(4), 459-474.

Lord, R. G., \& Maher, K. J. (1991). Cognitive theory in industrial and organizational psychology. Handbook of industrial and organizational psychology, 2, 1-62. 
Machida, M., \& Schaubroeck, J. (2011). The role of self-efficacy beliefs in leadership development. Journal of Leadership \& Organizational Studies, 18(4), 459-468.

Martinez, K. Y., Ostick, D. T., Komives, S. R., \& Dugan, J. P. (2007). Lesbian, gay, and bisexual leadership and self-efficacy: Findings from the MultiInstitutional Study of Leadership. Concepts \& Connections, 15(2), 10-12.

McCormick, M. J., Tanguma, J., \& Lopez-Forment, A. S. (2002). Extending selfefficacy theory to leadership: A review and empirical test. Journal of Leadership Education, 1(2), 1-15.

Mori, S. (2000). Addressing the mental health concerns of international students. Journal of Counseling and Development, 78(2), 137-144.

Murphy, S. E. (2002). Leader self-regulation: The role of self-efficacy and multiple intelligences. In Kravis-de Roulet Leadership Conference, $9^{\text {th }}$ Apr, 1999, Claremont McKenna Coll, Claremont, CA, US.

Owie, I. (1982). Social alienation among foreign students. College Student Journal, $16,163-165$.

Paglis, L. L. (2010). Leadership self-efficacy: Research findings and practical applications. Journal of Management Development, 29(9), 771-782.

Pascarella, E. T., \& Terenzini, P. T. (2005). How college affects students: A third decade of research. San Francisco: Jossey-Bass.

Renn, K. A., \& Arnold, K. D. (2003). Reconceptualizing research on college student peer culture. Journal of Higher Education, 74(3), 262-291.

Roberts, D. C. (2003). Crossing the boundaries in leadership program design. In Cherry, C., Gardiner, J. J., \& Huber, N. (Eds.), Building Leadership Bridges 2003. (pp. 137-149). College Park, MD: International Leadership Association.

Robertson, M., Line, M., Jones, S., \& Thomas, S. (2000). International students, learning environments and perceptions: A case study using the Delphi technique. Higher Education Research \& Development, 19(1), 89-102.

Rohs, F. R. (1999). Response shift bias: A problem in evaluating leadership development with self-report pretest-posttest measures. Journal of Agricultural Education, 40(4), 28-37.

Rohs, F. R. (2002). Improving the evaluation of leadership programs: Control response shift. Journal of Leadership Education, 1(2), 1-12.

Rohs, F. R., \& Langone, C. A. (1997). Increased accuracy in measuring leadership impacts. Journal of Leadership Studies, 4(1), 150-158.

Ronen, S., \& Shenkar, O. (1985). Clustering countries on attitudinal dimensions: A review and synthesis. Academy of management Review, 435-454.

Rost, J.C. (1991). Leadership for the twenty-first century. New York: Praeger.

Schram, J. L., \& Lauver, P. J. (1988). Alienation in international students. Journal of College Student Development, 29(2), 146-150.

Smith, P. B., Dugan, S., \& Trompenaars, F. (1996). National culture and the values of organizational employees a dimensional analysis across 43 nations. Journal of cross-cultural psychology, 27(2), 231-264.

Spencer-Rodgers, J. (2001). Consensual and individual stereotypic beliefs about international students among American host nationals. International Journal of Intercultural Relations, 25(6), 639-657. 
Tabachnick, B. G., \& Fidell, L. S. (2007). Using multivariate statistics (5 ${ }^{\text {th }}$ ed.). Boston, MA: Pearson Education.

Tomich, P. C., McWhirter, J. J., \& Darcy, M. U. A. (2003). Personality and international students' adaptation experience. International Education, 33(1), 22-39.

Toyokawa, T., \& Toyokawa, N. (2002). Extracurricular activities and adjustment of Asian international students: A study of Japanese students. International Journal of Intercultural Relations, 26(4), 363-379.

Tseng, W-C., \& Newton, F. B. (2002). International students' strategies for wellbeing. College Student Journal, 36(4), 591.

Yi, J. K., Lin, J. G., \& Kishimoto, Y. (2003). Utilization of counseling services by international students. Journal of Instructional Psychology, 30(4), 333342.

Zimmerman-Oster, K., \& Burkhardt, J. (1999). Leadership in the making: Impact and insights from leadership development programs in U.S. colleges and universities. Battle Creek, MI: W.K. Kellogg Foundation..

DAVID H. K. NGUYEN, MBA, JD, LL.M. adv., PhD, is an assistant professor of educational leadership in the Higher Education program and affiliate assistant professor of law at the University of North Dakota, Grand Forks, ND. Dr. Nguyen's research interests include examining international student experiences on campus and the intersections of law and policy on the inequitable policies and practices of access for underrepresented students. Email: david.hk.nguyen@und.edu. 